\title{
Introdução da comunicação suplementar e alternativa na terapia com afásicos
}

\author{
Introduction of augmentative and alternative communication \\ in aphasia therapy
}

\author{
Juliana Ferreira Marcolino Galli' ${ }^{1}$ Jáima Pinheiro de Oliveira²$^{2}$, Débora Deliberato ${ }^{3}$
}

\begin{abstract}
RESUMO
Sabe-se que o tratamento fonoaudiológico de pacientes com afasia severa é limitado. A ausência de fala articulada, algumas vezes, impede o diagnóstico da afasia. O paciente "grave" pode não falar devido à inabilidade de articulação, como ocorre na disartria e/ou apraxia. Essa ausência de fala não permite afirmar se a linguagem está comprometida. O uso da comunicação suplementar e alternativa tem sido um método eficaz na reabilitação desses pacientes. Esse estudo visou descrever o uso da comunicação suplementar e alternativa associada a outras modalidades de linguagem (escrita, gestos), a partir do relato de dois casos de afasia. A análise dos dados foi composta por dois blocos: a introdução da comunicação suplementar e alternativa no diálogo; e o uso da leitura e escrita associado aos símbolos. A comunicação suplementar e alternativa foi um apoio para a oralidade, leitura e escrita dos pacientes.
\end{abstract}

Descritores: Afasia; Fonoterapia; Comunicação não verbal; Relatos de casos

\section{INTRODUÇÃO}

A afasia é uma perturbação na fala e/ou na escrita após uma lesão cerebral adquirida. Na maioria dos casos, há manifestações associadas, tais como: comprometimentos visuais, auditivos, paralisias ou paresias de membros superiores e/ou inferiores, quadros de disartria e/ou apraxia, disfagia, problemas emocionais e sociais. As alterações na fala exigem, ainda, um diagnóstico diferencial entre disartria, dispraxia e distúrbios de fluência. No estudo ${ }^{(1)}$ com 192 pacientes neurológicos, 70\% eram afásicos, $6 \%$ com disartria e apraxia, $17 \%$ com alterações funcionais de comunicação e $7 \%$ eram normais.

O paciente denominado, neste trabalho, como "grave" é aquele que não fala ou escreve. Algumas vezes, há voz, ou seja, há sons ininteligíveis, marcados por estereotipias e jargões. Não há, nesses casos, fala articulada, resquício de

Trabalho realizado na Clínica Escola de Fonoaudiologia da Universidade Estadual do Centro-Oeste - UNICENTRO - Irati (PR), Brasil.

(1) Mestre, Professora do Departamento de Fonoaudiologia da Universidade Estadual do Centro-Oeste - UNICENTRO - Irati (PR), Brasil.

(2) Mestre, Professora do Departamento de Fonoaudiologia da Universidade Estadual do Centro-Oeste - UNICENTRO - Irati (PR), Brasil.

(3) Doutora, Professora do Departamento de Educação Especial e do Programa de Pós-Graduação em Educação da Faculdade de Filosofia e Ciências da Universidade Estadual Paulista Júlio de Mesquita Filho - UNESP - Marília (SP), Brasil.

Endereço para correspondência: Juliana Ferreira Marcolino Galli. PR 153, Km 07, Riozinho, Irati (PR), Brasil, CEP: 84500-000.

E-mail: jumarcolino@terra.com.br

Recebido em: 8/12/2008; Aceito em: 18/5/2009 escrita para ser escutado/interpretado. Restam apenas gestos e olhares. Nossa experiência mostra que muitos desses pacientes "graves" não conseguem a repetição, o esboço articulatório é frustrante e a evolução é limitada.

A ausência de fala articulada, algumas vezes, impede o diagnóstico da afasia. O paciente "grave" ou portador de afasia crônica possui ausência de fala devido à inabilidade de articulação, como ocorre na disartria (anartria) e/ou dispraxia (apraxia) severa, ou ainda, pode apresentar uma fala ininteligível com presença de jargões e neologismos. A ausência de fala não permite afirmar se a linguagem está comprometida, ou melhor, se é um caso de afasia. Pode-se dizer que os casos neurológicos "graves" dificultam o diagnóstico e o tratamento fonoaudiológico.

A apraxia/dispraxia de fala é definida como um transtorno da comunicação caracterizado por dificuldade em posicionar e sequencializar os órgãos fonoarticulatórios para a produção de sons. O paciente "sabe" a palavra a ser dita, mas não consegue sequenciar o ato motor. Trata-se de um distúrbio sensório-motor na capacidade de selecionar, programar e/ou executar produção de sons voluntariamente ${ }^{(2)}$.Essa definição, no entanto, não esclarece a natureza dos sintomas. Isso porque, os estudos neurolinguísticos têm identificado uma grande polêmica, a saber: as repetições e substituições dos fonemas caracterizam um distúrbio na linguagem ou na fala? Em outras palavras, essa questão toca na dicotomia fonético versus fonológico. É uma perturbação motora na fala (fonética) ou na linguagem (nível fonológico)?

É interessante notar que, mesmo diante deste questiona- 
mento teórico, a reabilitação parece ignorar a polêmica. O que se vê, como proposta de tratamento da apraxia, é o treinamento isolado de sons, como a terapia dos "oito passos"(3), deixando o linguístico marginalizado. Além disso, no caso de pacientes "graves" não é possível o treinamento isolado de sons devido à severa dificuldade em produzi-los.

Outra opção no tratamento de afásicos severos é a terapia melódica. Geralmente, frases curtas com acentuação melódica diferente da fala normal são treinadas. Aos poucos, retira-se o apoio melódico para aproximação de uma prosódia normal da fala. Limitações desse método são descritas pela literatura ${ }^{(4)}$. Temos evidenciado que, em alguns casos, não é possível a retirada do apoio melódico.

Outra pesquisa $^{(5)}$ relatou o caso de um paciente com impossibilidade de oralizar. A terapeuta, nesse caso, tomava o fletir e o levantar a cabeça como "não" e "sim" do paciente, já que a compreensão parecia preservada. Após alguns meses de atendimento, o paciente pareceu "recuar" à proposta terapêutica. Diante deste "insucesso", como autora questiona se há um limite para a clínica de linguagem. Ela acredita que, nesse caso, há um desvio no tratamento da linguagem, o qual foi essencialmente de motricidade orofacial.

O tratamento miofuncional é, de fato, um passo inicial para produção de algum som. Muitas vezes, o aumento do suporte respiratório retira o paciente da condição de ausência de fala. Em alguns casos, após melhora da articulação, fonação e respiração pelo tratamento da musculatura respiratória e orofacial, a fala que se apresenta é ininteligível, é um jargão. Após a melhora da musculatura orofacial, a dificuldade de linguagem fica escancarada. Outros pacientes, ainda, se beneficiam do trabalho miofuncional para as alterações de mastigação e deglutição com a fala ausente.

Diante desses impasses no tratamento de pacientes neurológicos graves, temos utilizado o sistema suplementar e/ou alternativo de comunicação com o objetivo de "ceder voz ao paciente"(5). É através dos símbolos que o paciente pode se assumir como falante e sustentar um dizer.

A comunicação suplementar e alternativa (CSA) pode ser definida como "todo e qualquer recurso que pode ser utilizado para codificar e transmitir uma mensagem, sem requerer habilidades de escrita ou vocalização"(6). Pode ser considerada uma área de atuação clínica com o objetivo de compensar uma alteração severa da comunicação( ${ }^{(7)}$.

O uso de símbolos na comunicação não impede o surgimento da oralidade. $\mathrm{O}$ sistema permite, espontaneamente, a emissão oral quando o paciente aponta as figuras. Além disso, a disposição das figuras preserva a sintaxe da língua ${ }^{(8)}$.

Sobre o uso de sistemas suplementares e alternativos de comunicação no processo terapêutico com afásicos, embora estudos sejam escassos, a literatura aponta esses sistemas como facilitadores da comunicação, ou seja, como recursos de reabilitação da fala e facilitação da comunicação em situações do dia-a-dia. Encontram-se, também, descrições de adaptações e uso de sistemas de alta tecnologia, em sua grande maioria, para casos de paralisia cerebral ${ }^{(6,9-10)}$.

Alguns pesquisadores ${ }^{(9)}$ descreveram o uso de um software desenvolvido especificamente para o treinamento de conversação com três indivíduos com afasia. Esses participantes tinham afasia crônica (Broca, Wernicke e anômica) e foram avaliados antes e depois de nove semanas de uso do programa. Para cada participante, três tarefas individualizadas foram desenvolvidas em casa, gravadas e praticadas de modo sequencial. Encontros semanais com o terapeuta ocorreram para monitorar a prática e avaliar o progresso dos pacientes. Os resultados indicaram que todas as medidas (produção gramatical, taxa de produção de palavras) melhoraram para cada participante, em cada uma das tarefas. Os autores concluíram que o treinamento das tarefas com o uso de computador pode ser uma intervenção eficaz para pessoas com afasia crônica.

Em uma revisão de literatura sobre a comunicação alternativa no campo da afasiologia, autores ${ }^{(11)}$ verificaram que as publicações feitas se referem ao uso desse recurso como suporte (com e sem apoio) para os contextos de terapia, nos quais se encontram estes indivíduos. Nesse estudo, os autores identificaram que os ganhos se referem à comunicação de rotina em ambiente domiciliar, sem generalização para outros ambientes e sem uma exigência maior em relação à comunicação destes pacientes. Ressalta-se, porém, que os estudos analisados pelos autores, envolveram intervenções com comunicação alternativa para adultos com afasia severa. Os autores concluíram que o uso destes recursos com as pessoas com afasia severa deve ser dirigido para os fatores fora do ambiente de tratamento.

Observa-se que os escassos trabalhos sobre o tema apenas mencionam a utilização deste recurso em afasias crônicas ou severas. Em sua grande maioria, as pesquisas não relatam como um trabalho pode ser implementado.

O objetivo deste trabalho é descrever o uso da comunicação suplementar e alternativa associada a outras modalidades de linguagem (escrita, gestos), a partir do relato de dois casos de afasia. Nesse relato, enfocaremos que há singularidades no processo terapêutico.

\section{APRESENTAÇÃO DOS CASOS CLÍNICOS}

As duas pacientes afásicas, M. e J. são atendidas na Clínicaescola de Fonoaudiologia e Psicologia da Universidade Estadual do Centro-Oeste (UNICENTRO), Campus de Irati (PR).

M. tem 66 anos de idade e sofreu um Acidente Vascular Encefálico Isquêmico (AVEI) 12 meses antes da procura pelo tratamento fonoaudiológico. O exame neurológico indicou lesão frontoparietotemporal no hemisfério esquerdo. M. apresenta, ainda, paralisia no braço direito, agnosia visual*, a qual foi detectada, somente, na avaliação fonoaudiológica e necessita de cadeiras de rodas para se locomover. Ela é viúva e reside com a sua filha. Durante o dia, ela assiste à televisão e não realiza outra atividade. Na entrevista, a paciente entrou sozinha na sala de atendimento, a pedido da terapeuta. Já na recepção, a filha de M. disse "ela não fala nada". No final da sessão, a filha entrou para relatar as dificuldades da mãe e afirmou que a fala de M. é incompreensível. No entanto, com o uso de gestos, M. consegue enunciar uma queixa, mostrando a região da boca e pescoço, lamentando-se pelo ocorrido.

\footnotetext{
* Agnosia visual: incapacidade de reconhecimento visual de objetos com preservação da via ótica.
} 
Com perguntas fechadas, que exigiam respostas como "sim" e "não", a terapeuta pode recolher algumas informações, como por exemplo, o número de filhos que a paciente teve.

Durante avaliação, foi possível observar que a paciente apresenta compreensão intermitente. Ou seja, ela compreende parcialmente a fala da terapeuta. Muitas vezes, sua expressão era de dúvida sobre o que a terapeuta lhe pedia. Ela respondia satisfatoriamente às ordens simples e com dificuldades às ordens complexas. Ela lê somente algumas palavras mais familiares, apesar de ter sido alfabetizada. $\mathrm{O}$ uso de gestos no diálogo é restrito, com pouca mudança de entonação na fala. Ela não consegue repetir e a nomeação é caracterizada por fala jargonafásica**. M. tem apraxia severa de fala e de órgãos fonoarticulatórios. O uso de figuras permitiu verificar que ela tinha dificuldades de reconhecimento visual. Em alguns momentos, a paciente permanecia um longo tempo olhando as figuras com expressão de dúvida, sendo que, em outras sessões, as figuras já tinham sido reconhecidas. Essa heterogeneidade (ora reconhece, ora não reconhece a mesma figura) caracteriza a agnosia visual.

A paciente M., ainda, não recusa a interpretação da terapeuta, pois ela sempre diz "sim" com meneio de cabeça. Diante disso, temos duas possibilidades, sendo que uma não exclui a outra: (a) a paciente possui dificuldades de compreensão, a qual foi comprovada em outras situações; (b) o corpo também responde como um jargão, sempre fazendo "sim"****.

O segundo caso é J., 44 anos, que sofreu um AVEI seis meses antes do início do tratamento fonoaudiológico. O exame neurológico indicou lesão em região parieto-occipital esquerda. Na entrevista, J. entrou sozinha e tentou enunciar a queixa diversas vezes: ela dizia sons ininteligíveis, balançava a cabeça negando sua própria fala, parava, retomava sua fala numa nova tentativa, mas frustrada. No entanto, ela consegue utilizar gestos e responde às perguntas da terapeuta. Desde o início, J. marca sua posição para o atendimento: ela não desiste diante da dificuldade e pede o seu lugar de falante ao outro.

A avaliação fonoaudiológica observou presença de dispraxia severa de OFA e de fala. Alguns pedaços de palavras, como "bô", "ô", "bom", "é", apareceram esporadicamente. A compreensão da paciente está preservada em narrativas, piadas e ordens complexas. J. foi alfabetizada e consegue identificar todas as letras do alfabeto, mas não consegue escrever sozinha. Quando a terapeuta dita as letras separadamente, ela consegue escrever algumas palavras. Não consegue nomear devido a dispraxia. J. consegue repetir palavras com imprecisão e dificuldades articulatórias. Há melhora da repetição após várias tentativas. Na coleta de dados deste trabalho, ela encontrava-se em atendimento fonoaudiológico há cinco meses.

As pacientes iniciaram o uso da CSA na época da coleta de dados.

A indicação de uso da CSA respeitou os critérios já descritos pela literatura ${ }^{(7)}$, tais como: acuidade visual e auditiva, percepção auditiva e visual; controle de postura e motor, estabilidade emocional, desenvolvimento cognitivo, intenção comunicativa, entre outros. Nossa prancha de CSA foi confeccionada em car- tolina preta e 30 figuras foram coladas. As figuras pertencem ao sistema de software livre disponibilizado na internet pelo projeto AMPLISOFT da Pontifícia Universidade Católica do Paraná. No canto esquerdo da cartolina, foram colados os símbolos de pronomes pessoais; ao lado ficaram os símbolos de verbos e, no canto direito, os símbolos de substantivos, obedecendo, assim, à sintaxe da língua portuguesa (sujeito-verbo-objeto). A prancha era temática (refeições; atividades de lazer).

Três sessões de terapia fonoaudiológica com as pacientes foram gravadas em vídeo. Essas gravações foram iniciadas a partir dos dez primeiros minutos de terapia e duraram, em média, 15 minutos, sendo tomados para análise os dez minutos finais. A análise dessas sessões procurou descrever os eventos comunicativos (gestos, fala, dentre outros) do terapeuta e dos pacientes.

O presente estudo respeitou todas as normas estabelecidas pela resolução 196/96, acerca dos aspectos éticos em pesquisas com seres humanos. A mesma só teve seu início, após a devida autorização da instituição, bem como, após a leitura e concordância, obtida por meio da assinatura do Termo de Consentimento Livre e Esclarecido (TCLE) por um familiar, após serem explicitados objetivos e procedimentos a serem realizados, tanto para o familiar, como para a paciente. A pesquisa foi avaliada e recebeu parecer favorável para sua realização, pelo Comitê de Ética em Pesquisa da Universidade Estadual do Centro-Oeste (UNICENTRO), Campus de Guarapuava (PR), estando registrada sob número 05601/2008.

Para melhor apresentação dos casos, tomamos dois blocos de análise: (1) a introdução da comunicação suplementar e alternativa (CSA) no diálogo e (2) o uso da leitura e escrita associado aos símbolos.

\section{A introdução da CSA no diálogo}

\section{Paciente $M$.}

Como M. apresenta agnosia visual, a CSA não foi primeira opção terapêutica. O tratamento foi iniciado por exercícios com sequências motoras para a apraxia de órgãos fonoarticulatóricos (OFA), tais como: bico-sorriso, língua tocando nos cantos da boca, Após algumas semanas, M. já tinha melhor controle voluntário de OFA, mas não conseguia realizar emissões voluntárias. Para a apraxia de fala e ausência de oralidade, iniciamos por repetição de fonemas plosivos bilabiais e, também, pela terapia melódica. A paciente apenas emitiu /pa/, perseverando os movimentos e não teve evolução. Na terapia melódica, ela conseguiu acompanhar a melodia do terapeuta. No entanto, não conseguiu nenhuma vez sem apoio da fala do terapeuta. Diante da pouca evolução, a CSA foi uma alternativa. Esperava-se que, com um tema estabelecido pelas figuras (por exemplo: café da manhã), um diálogo entre terapeuta e paciente pudesse ocorrer com maior facilidade. Nesse diálogo, M. poderia usar gestos, apontar figuras, oralizar e ler os nomes das figuras correspondentes. Apostou-se que o cruzamento entre diversas modalidades (escrita, fala, gestos, símbolos) pode favorecer mudanças na linguagem.

\footnotetext{
** Fala jargonafásica: fala ininteligível que o paciente repete sempre que tenta dizer algo.

*** Perseveração é um sintoma freqüente na afasia. É a repetição de uma resposta anterior.
} 
A indicação dos símbolos, nesse caso foi, principalmente, pela presença do jargão "taran" em todas as tentativas de fala da paciente; o uso restrito de gestos e a dispraxia severa não responderam aos exercícios isolados. Diante desse quadro, dificilmente a paciente poderia contar algo; ela apenas respondia "sim" e "não" com meneios de cabeça.

As sessões são dirigidas em sua maior parte por perguntas. No entanto, as perguntas são "fechadas", pois não exigem respostas narrativas, descritivas ou argumentativas. Todas as perguntas dirigidas devem seguir um padrão de resposta simples, como o "sim" e o "não", para que os meios utilizados para responder possam ser diversificados e voltados, não somente para a oralidade, mas para um gesto, ou simplesmente que apontem um símbolo. Ao mesmo tempo, esse diálogo sempre abria possibilidades para a oralidade.

Para que haja fluência nesse diálogo, os símbolos são familiares, de fácil reconhecimento pelo paciente ou que façam parte de sua rotina. Desse modo, utilizou-se um sistema bastante icônico, conforme projetado pelo software já mencionado. A prancha foi temática. Na maioria das sessões, utilizou-se o tema refeições para a paciente iniciar a CSA em casa, logo. $\mathrm{Na}$ prancha "refeições", as figuras representavam diversos alimentos (pão, leite, carne), ações (comer, beber, preparar) e tempos (manhã, tarde, noite, ontem, hoje). A terapeuta iniciava o diálogo perguntando sobre os alimentos preferidos; o que comeu ontem, etc.

O primeiro momento, no caso de M., foi específico para o reconhecimento de símbolos devido a agnosia visual. No final da sessão, M. levava a prancha para casa somente para dar significado às figuras.

A seguir, tem-se um exemplo de trecho de diálogo, indicando os aspectos considerados, no qual a terapeuta (T) trabalha o reconhecimento de símbolos que fazem parte de ações do dia-a-dia da paciente $(\mathrm{P})$. Este trecho traduz parte do início da implantação do sistema de símbolos. As primeiras sessões com a prancha de comunicação foram marcadas pelo reconhecimento de poucas figuras e elaboração de frases simples.

- Fragmento $1:$ :04/05/2007

T: Esse é escovar dente, não é? Qual é esse aqui?

$P$ : Taran...

T: Faz o gesto pra eu ver. Qual que é esse?

$P$ : Taran... (fazendo o gesto de escovar os dentes)

T: E esse daqui, faz o gesto pra mim ver?

$P$ : Tadan... (fazendo o gesto correto)

T: Ah... então vamos falar que a menina tomou banho?

P: Tadan... tadan.... (sem fazer gestos)

T: Peraí! Vamos falar que a menina tomou banho. Aponta pra mim?

P: Taran... taran...

T: Aponta aqui...

P: Taran... tadan (aponta a figura da menina)

T: Tá! Só a menina. O que ela fez mesmo?

P: Tadan (fazendo gesto com a mão passando pelo corpo)

T: Tá. Então aponta pra mim, onde tá o que ela fez?

P: Tadan... tadan... (a paciente fica um tempo com o dedo sobre as figuras como se estivesse procurando)

T: Aponta pra mim, o gesto só não vale.
P: Tadan... (colocando a mão sobre todas as figuras).

T: Olha aqui (apontando a figura do banho). Perdeu de novo onde que tava?

P: Tadan. (apontando a figura do banho)

T: Quem toma banho?

P: Tadan.

Pode ser observado que M., em alguns momentos, mostra dificuldade em utilizar os gestos significativos. Vemos que há uma dificuldade em reconhecer os símbolos para dar continuidade ao diálogo e também há restrição para gestos. Há alguns trechos que indicam que a paciente demonstra compreensão no diálogo, sem o uso de símbolos, embora seja apenas com perguntas fechadas.

Outro sintoma característico dessa paciente é a perseveração. Quando a paciente consegue produzir um gesto ou um som, ela insiste no mesmo, persevera e dificilmente consegue produzir algo diferente. É interessante destacar que essa perseveração também apareceu no uso dos símbolos. Os fragmentos 2 e 3 indicam tal possibilidade.

- Fragmento 2: 11/05/2007

T: Então vamos lá... vamos; por que a família saiu pra praia.

P: Hum...

T: Sabe qual que é?

P: Tadan...

T: Então vamos achar aqui. A família...

P: Tadan...

T: Vamos lá que você acha. Você acertou outro dia.

$P$ : (aponta as figuras de três pessoas, separadamente)

T: Não! A família. Tem uma figura que tá todo mundo junto. Não separado assim. (apontando as figuras que a paciente havia apontado) Tá todo mundo junto.

$P:$ Tan... (apontando uma figura que tinha uma família)

T: É tem a família aqui. A família... A família saiu. Qual aqui. (mostrando a parte de verbos da prancha) Qual daqui que é o saiu?

P: Taran. (apontando pra a figura de esperar)

T: Qual que é esse? Esse é esperar. Olha o reloginho aqui. E esse aqui? (apontando a figura de sair) Não é esse?

P: Tadan. (apontando a figura de sair junto com a terapeuta)

T: É esse, olha. Pra onde a família foi? Saiu pra onde? (apontando as figuras de família e sair)

P: Tadan...

T: Onde ta a figura da praia?

P: Tan. (apontando a figura da família)

T: Não. Da praia. Da praia. Aqui olha pra esse lado de cá. (apontando na prancha)

Tá enxergando essa fileira aqui? Tá enxergando?

P: Hum...

T: Aqui, olha pra esse lado de cá... mais pra cá...

P: Tadan... (apontando a figura do feijão)

T: O que é isso aí?

P: Tadan... (apontando o açúcar)

T: Esqueceu o que a gente tava falando? Esqueceu? Você tá falando do feijão, (apontando a figura que a paciente havia 
apontado) do açúcar. (apontando a figura) Esqueceu que a gente tava falando da praia, olha? (apontando a figura da praia)

$$
\text { P: Taran... }
$$

- Fragmento 3: 11/05/2007

T: Vou deixar agora prá senhora escolher a figura que a senhora quer. Escolhe qualquer uma pra senhora me contar alguma coisa. Só que tem ser uma frase. Tem que ter uma daqui, uma daqui e uma daqui. (apontando para as fileiras da prancha)

P: Tão... (apontando a figura do filho)

T: O filho... o que o filho fez?

P: Taran. (apontando a figura da filha)

T: O filho e a filha?

P: Taran. (apontando mais uma figura sem especificar bem)

T: Hum? Não entendi nada $M$.

P: Tataran...

T: Escolhe uma só, pra gente tentar...

P: Taran... tan. (apontando a figura da menina dentro da figura de família)

T: Você tá apontando só essa menina aqui ou todo mundo que ta aqui?

P: Taran...

T: Não entendi.

P: Taran. (fazendo o gesto de todo mundo)

T: Todo mundo?

P: Taran. (fazendo gesto positivo com a cabeça)

T: Tá. Então vamos lá... Então, a família toda... (apontando pra figura) Escolhe uma figura daqui agora. (apontando pra fileira de verbos) $O$ que aconteceu?

P: Taran. (apontando pra figura de visitar)

T: Saiu ou foi visitar?

P: Taran... (visitar)

T: Quem que ela foi visitar?

P: Tadan. (apontando a figura da família) Tadan. (apontando a figura de sair)

T: Quem ela foi visitar?

P: Tadan. (apontando a figura de sair)

T: Saiu?

P: Tadan...

T: Então a família (apontando a figura da família) saiu. (apontando a figura de sair)

\section{P: Taran}

T: E pra onde que a família foi?

P: Tadan. (apontando toda a prancha)

T: Foi passear? Só foi passear?

P: Hum.

T: Então tá bom.

T: Agora é minha vez de falar o que a senhora tem que escolher. É... vai falar que o menino comeu fruta.

P: Tan...

Podemos observar que no início, no Fragmento 2, a terapeuta estava solicitando à paciente que formulasse a seguinte frase: "A família saiu para a praia". Após várias tentativas, a frase é formulada parcialmente. Após mudarem de tema, na mesma sessão, a paciente retornou a essa primeira proposta. Ressalta-se, porém, que essa atitude é frequente nas sessões de M., o que nos permite afirmar que se trate de uma "fala" perseverativa.

Por esse motivo, a introdução do CSA foi restrita a um tema da prancha durante oito sessões. $\mathrm{O}$ tema não foi modificado neste período. Isto facilitou o reconhecimento das figuras e a continuidade do diálogo e melhora da compreensão.

O sintoma de perseveração, também presente nos símbolos e a dificuldade da M. para sustentar um dizer, nos mostra que ela tem uma patologia de fala e de linguagem. M. possui dificuldades para escolher um símbolo e quando aponta são os mesmos símbolos das sessões anteriores.

Apesar de a agnosia visual ser um critério que deveria excluir a paciente M., o insucesso de outras técnicas como já dissemos, determinou a escolha dessa via alternativa, a qual mostrou ser efetiva.

\section{Paciente J.}

A CSA foi introduzida como primeira opção no tratamento de J. Isso porque, a nossa experiência clínica com pacientes afásicos "graves" sugere que é um caminho viável para mudança linguística, sendo que sempre investimos em todas as modalidades de linguagem quando o CSA está em uso. Por exemplo, com uma prancha sobre o tema "café da manhã", a terapeuta pergunta à paciente "o que ela come nesta refeição". A resposta é o apontar para os símbolos e, após, repetição, leitura e escrita dessas palavras com apoio do terapeuta****.

No caso da paciente J., o diálogo tem um caráter mais abrangente, no sentido deste fluir por meio de gestos, tentativas aproximadas de emissões orais e indicação coerente dos símbolos. J. não tem dificuldade em relação ao reconhecimento dos símbolos, o que facilita sobremaneira o diálogo. O Fragmento 4 exemplifica tais situações.

- Fragmento 4: $3^{\mathrm{a}}$ sessão em Novembro/2007

T: O que vc. acha que é essa figura aqui? A B. é sua...

P: Kika (filha)

T: Eo G. é seu...

P: Kiko (filho)

T: A L. não é mais uma menina, ela é uma...

$P$ : Ié... (mulher)

T: Mulher... Você tem mãe viva?

P: Não... (fazendo gesto negativo com a cabeça)

T: Morreu você era muito jovem?

$P:$ (fazendo gesto positivo com a cabeça)

T: Você já era uma menina, ou já era uma mulher?

P: Bô... (colocando a mão sinalizando altura)

T: Você era uma menina. Tinha quantos anos? Mostra pra mim nos dedos.

P: Kê... bô... bô... (fazendo gestos com dedos, ora três, ora quatro)

T: Cinco?

**** O modo de disposição das figuras e a escolha dos símbolos para a prancha temática foi igual às escolhas realizadas para M, já descritas acima e na metodologia. 
P: Bô... (fazendo gesto negativo com a cabeça)

$P: B \hat{o} \ldots$ bô... (4 dedos)

T: Quatro anos?

P: Não... bôbô... (fazendo gesto negativo com a cabeça)

T: Não era 4.

P: Não... dô... gô...

T: Deixa só eu entender. Você era muito criança ou já era adolescente?

$P: E$ E.. é... (fazendo sinal com a cabeça de positivo)

T: E você tinha irmãos menores?

$P$ : É... (fazendo gestos com dedos)

P: Tem... (fazendo gestos com dedos, indicando 4)

T: Todos vivos? Você tem contato com eles? Moram aqui em Irati?

P: Dem... é... é... (fazendo gesto positivo com a cabeça)

T: E aí, tinha que cuidar de todos os irmãos?

$P:$ Não... não...

T: hum...

$P$ : ôô... (apontando pra ela mesma)

T: Você tinha irmã mais velha?

P: ôo... (apontando pra ela mesma)

T: Você é a mais velha?

$P$ : ôo... (fazendo gesto positivo com a cabeça)

O Fragmento 4 confirma que J. não tem dificuldade para reconhecer os símbolos e, em relação à oralidade, existem tentativas de aproximação dos nomes dos símbolos. Por outro lado, mesmo com um desempenho melhor, observa-se como no caso de $\mathrm{M}$. que o diálogo também é marcado por perguntas fechadas, isto é, todas as perguntas dirigidas devem seguir um padrão de resposta simples, como o "sim" e o "não". Só que nesse caso, é interessante notar que J. utiliza todos os recursos comunicativos. Isso indica que os símbolos ampliam as possibilidades de comunicação, com foco para a oralidade.

Além disso, observa-se nesse caso que o recurso alternativo configura-se como uma troca e um apoio, para o surgimento de temas para o diálogo entre a terapeuta e a paciente. Em outras palavras, poderíamos dizer que a prancha deflagra o diálogo entre os sujeitos, sendo, portanto, um apoio fundamental para a oralidade.

Isso pode ser confirmado em outro fragmento no qual pode ser observado que a paciente utiliza todos os recursos possíveis em sua comunicação (fala, gestos, símbolos), quando está descrevendo os símbolos da prancha.

- Fragmento 5: $5^{\mathrm{a}}$ sessão em Novembro/2007

T: Vamos ver o que tem aqui do café da manhã?

P: (olhando para a prancha)

T: Então... tem leite.

P: Le... lei... te (apontando o símbolo)

T: $\mathrm{Ca} \ldots$

$P:$ Rô... (apontando o café)

T: Fé.

$P: \hat{E} \ldots . . . .$.

T: Como se fosse um assopro, olha: (terapeuta assopra olhando para a paciente) Assopra vai...

P: (fecha a boca tentando imitar a terapeuta) aaaa....
T: Ca... fffffff... fé...

$P:$ (tentando fazer o gesto articulatório do fonema /f/) pô...

T: Então tem leite, café, pão...

P: Pô.

T: E o que a gente faz de manhã? Que tem ainda aqui que a gente faz de manhã?

$P$ : Rô... (apontando a figura do banho)

T: Ó... depois que acorda...

P: I... (apontando a figura de escovar dos dentes) bô...

(fazendo o gesto de escovar os dentes)

T: Ah! Você tá falando de escovar?

P: É... (repete o gesto de escovar os dentes)

T: Aqui não é? (apontando a figura de escovar os dentes)

P: É... bô...

T: Então espera aí, acorda e depois...

P: De... kê... (dente)

T: Dentes. Escovar os dentes. Então eu acordo e escovo os...

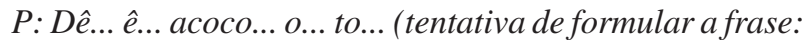
eu acordo e escovo os dentes)

T: Foi bem no começo e depois piorou... Vamos de novo? Eu acordo e escovo os...

P: Quê... dê...

A facilidade de J. para utilizar símbolos, gestos e iniciar vocábulos orais questiona a ausência ou presença da afasia. Sabe-se que J. tem dificuldade para oralizar devido a dispraxia e disartria severa. A ausência de fala não permite o diagnóstico da afasia, a qual poderia aparecer no uso de símbolos.

\section{O uso da leitura e escrita associado aos símbolos}

\section{Paciente M.}

O uso da leitura e da escrita, associadas aos símbolos, melhora o desempenho comunicativo das duas pacientes, embora haja dificuldade motora fina em ambos os casos. Observa-se nos fragmentos a seguir, que esse uso configurase como recurso complementar de extrema importância na terapia fonoaudiológica.

No caso de M, a leitura e a escrita estavam severamente prejudicadas. Na leitura, a paciente apenas lia o seu nome. Cabe destacar que a paciente foi alfabetizada e fazia uso da escrita nas suas tarefas diárias como dona-de-casa, antes da lesão cerebral.

A partir disso, embaixo de cada símbolo há o seu correspondente escrito. As figuras eram utilizadas na terapia e depois, a paciente levava a prancha para casa. O uso da prancha em casa foi, aos poucos, possibilitando a leitura dos símbolos pela paciente M. Além disso, o reconhecimento dos símbolos passou a ficar mais fácil, promovendo maior fluência ao diálogo. Vejamos o Fragmento 6.

- Fragmento 6: 22/06/2007

T: Agora eu vou escrever outra coisa... com outra letra agora pra ver se fica mais fácil. (escreve a palavra feijão numa folha e mostra à paciente)

$P$ : Tan tan... tão. (como se estivesse lendo o que a terapeuta escreveu na folha) 
T: Onde tá isso aqui (indicando a prancha)? Mostra pra mim.

P: Dandan... (apontando a figura de feijão)

T: Aí! Fei...

P: Dão.

T: Aí! Mais uma agora... olha aqui... (mostrando a folha à paciente, após escreve outra palavra)

P: Tandan... dan. (como se estivesse lendo o que a terapeuta escreveu na folha)

T: Tá escrito aqui, olha? Onde tá aí (olhando para a prancha)? Vê se você consegue apontar..

P: Dandan. (apontando para mais de uma figura na prancha)

T: Car...

P: Dan.

T: Ne... Isso que a senhora leu?

P: Dan. (fazendo gesto afirmativo com a cabeça)

T: Onde ta a carne aí?

P: Taran.

T: Aqui! Achou!

P: Tadan.

T: Essa aqui tá mais fácil. (escrevendo outra palavra e mostrando à paciente)

P: Ta... ran. (apontando a figura corretamente na prancha)

T: Aí! Muito bem! Ta lendo bem. Agora, duas palavras juntas, hein? Vamos ver... tá muito fácil, hein? (escreve e mostra à paciente)

P: Tan... rão. (aponta corretamente na prancha)

T: Isso! Olha! (elogiando a paciente)

P: Tan. (risos)

T: Essa aqui! Tenta achar essa aqui (escreve e mostra à paciente)

P: Tandan.

T: Tá indo muito bem. Uma maior agora... (escreve e mostra à paciente)

P: Hum... (procurando na prancha)... tão?

T: Escovar os dentes! To impressionada com a senhora! Tá boa!

P: Hã (risos).

T: Agora vamos falar então?

P: Taran... taran.

T: Antes a senhora não lia... vamos tentar falar agora... tenta falar banana comigo... Ba...

$P: B a$.

T: Nan... na.

$P$ : Dão.

T: Isso!

Por outro lado, M. tem dificuldade com a leitura e a escrita com letras em "caixa alta" e tem muita dificuldade em ler palavras que não estão na prancha. Em uma sessão posterior, cujo fragmento será agora apresentado, houve tentativa por parte da terapeuta da paciente montar as palavras correspondentes aos símbolos trabalhados na prancha anteriormente, utilizando o alfabeto móvel. No entanto, M. demonstra dificuldade em tal tarefa, tanto para identificar na prancha os vocábulos produzidos pela terapeuta, quanto para produzi-los com o alfabeto móvel.
- Fragmento 7 : 29/06/2007

T: O que a gente toma no café da manhã? Procura isso aqui pra mim.

P: Dão. (sem apontar nada na prancha)

T: Café. Vamos escrever isso aqui? (a terapeuta escreve com o alfabeto móvel). O que está escrito aqui?

P: Dandan.

T: Ca...

P: Dan.

T: Isso! Café.

T: Vou escrever outra coisa que a gente toma junto com o café. Vamos lá... o que ta escrito?

P: Dandan.

T: Vê se tá aqui nas figuras?

P: Dandan.

T: Comer?

P: Tan.

T: Beber?

P: Dan.

T: Lei...

P: Dan.

T: Isso! Agora eu vou deixar as letras aqui e a senhora vai escrever café. Coloca na ordem. Vê se a senhora consegue colocar na ordem. Escreve café. Vamos pôr assim? Uma do lado da outra.

P: Tan... dan... dão.

T: Vou bagunçar... olha... escreve café.

P: Tandan... tandan. (coloca as letras de cima para baixo em ordem diferente)

T: Não. Não é assim que escreve.

$P$ : Dandan.

T: Tenta escrever então, olha?

P: Tandan... tandan.

T: Põe na ordem certa... tá na ordem errada. Qual é a primeira? Ca...

P: Tan... dan. (coloca as letras na ordem correta)

T: Aí! Tenta escrever aqui pra mim ó... café. (entregando a caneta e a folha pra paciente)

Paciente J.

Em relação ao desempenho da paciente J., podemos dizer que a leitura e a escrita são recursos complementares em relação ao seu processo terapêutico. A paciente só lia ou escrevia pedaços de palavras. A partir do uso da prancha de comunicação, as sessões seguiam assim: terapeuta e paciente conversavam através dos símbolos e, em seguida, a terapeuta separa letras de algumas palavras da prancha para J. montar. No início, J. fazia cópia, pois olhava a escrita na prancha e organizava as letras móveis. Aos poucos, Ela foi se desprendendo da cópia e passou a escrever em letra manuscrita. Além disso, como nas situações descritas anteriormente, ao escrever, a paciente emitiu esboços dos vocábulos de modo simultâneo. Isso indica novamente o auxílio destes recursos em relação à oralidade. Vejamos o Fragmento 8.

- Fragmento 8: $20^{\mathrm{a}}$ sessão

T: Vou separar as letras pra você escrever, hein? Já baguncei... (mexendo as letras separadas) Agora sim... Me... 
P: Me... ni... a... bé. (começando a juntar as letras)

T: Tá certo o começo...

P: Mi... no... lhe... (colocando as letras no lugar).

T: E essa letra aqui? (apontando a letra " $e$ ”) Onde vai?

$P: \hat{E}$... i... nô... abô? (fazendo gesto de acabou e procurando as letras)

T: Tá aqui ó....

P: Lhe... me... (termina de escrever a palavra corretamente)

T: De novo! Você vai escrever... menina come... coloca na ordem..

$P: / k / \ldots$ (emitindo o fonema $/ k /$ ) $/ k / \ldots$ (repete o som) abô...

T: Isso! Muito bem! A menina come... carne.

P: Ca... (olhando para a terapeuta e para as letras)

$T$ : Não vou escrever, vai você.

$P$ : (mexe com as letras, como se estivesse procurando)

T: Car... rrrrrr... ne.

P: Ca... a...

T: Tem som do r no meio, ó: carrrrrr... ne.

$P: \hat{E} \ldots \hat{e} . .$. (mexe com as letras) pa... no...

T: Ta quase lá. Olha aqui pra ver qual tá faltando?

$P: \hat{O} \ldots a$...

T: Eo "r"?

$P$ : (coloca o r na palavra e termina a frase)

T: Muito bom!

P: Bom... (sorri para a terapeuta)

O fragmento anterior é o resultado de 20 sessões terapêuticas que sempre articularam oralidade (repetição de palavras), escrita dos símbolos e diálogo deflagrado pela prancha de CSA.

Pode-se dizer que o trabalho com diversas modalidades de linguagem (oralidade, símbolos, gestos, leitura e escrita) produz mudanças significativas na linguagem. Além disso, o afásico toma seu lugar de falante.

\section{DISCUSSÃO}

Vimos que a CSA foi uma alternativa terapêutica para que os dois casos apresentados. J. e M. pudessem, cada um a seu modo singular, sustentar seu lugar de falante, o que é apontado na literatura como um dos principais objetivos da terapia com afásicos ${ }^{(5)}$.

As reflexões de outra autora ${ }^{(12)}$ alertam para que os gestos utilizados em terapia tenham efeito positivo fora desse contexto, precisam ter propriedades de linguagem, isto é, precisam expressar significados refinados, seletivos a serem expressos, consistentemente, como palavras únicas. Isto os fará diferentes dos gestos naturais que acompanham o discurso e dos gestos que possam estar desprovidos de significados, que também podem e devem ser utilizados na terapia.

A nosso ver, os gestos da paciente foram interpretados com linguagem, como uma tentativa de fala da paciente. Acreditamos que a interpretação desses gestos nas sessões possibilita seu uso fora do ambiente terapêutico. Isso porque, o trabalho concentrou na mudança estrutural da linguagem das pacientes. Ao assumir um lugar de falante e conseguir utilizar diversas modalidades de linguagem, o paciente não faz restrições de ambientes. É a mudança linguística que permite isso.

$\mathrm{Na}$ terapia com afásicos, é possível utilizar diversas modalidades de linguagem ao mesmo tempo, como símbolos, fala, gestos e escrita. O que se testemunha é o cruzamento da oralidade com a escrita numa relação de afetação mútua. Compartilhamos de uma ação clínica que se fundamenta no entrecruzamento fala-escrita: um jogo em que se colocam em relação à fala-escrita do terapeuta com a fala-escrita do paciente $^{(5,13)}$.

A literatura descreve o uso dos símbolos no caso de pacientes com afasias severas. Geralmente, esses pacientes não podem oralizar ou escrever. Concordamos que a indicação dos símbolos é para os casos severos de afasia, disartria ou e/ou dispraxia. Por outro lado, discordamos sobre o uso "alternativo".

Pode-se notar nos dois casos apresentados que o objetivo do uso dos símbolos é servir de apoio para deflagrar outras modalidades de linguagem. Nesse sentido, os símbolos é um apoio para oralidade e escrita. Ou seja, sua utilização não tem o sentido de "alternativo", quer dizer: o paciente não pode oralizar e escrever e, por isso, vai se comunicar com os símbolos. O sentido aqui empregado é terapêutico, pois esse sistema produz mudanças na fala e na escrita.

Nesse sentido, o ideal seria utilizar o termo "aumentativa ou o suplementar" para que seja transmitida a idéia de suporte para a fala e não de substituição. Os objetivos principais desse suporte seriam "promover e suplementar a fala e garantir uma forma alternativa de comunicação de um indivíduo que ainda não começou a falar"(14).

Alguns autores ${ }^{(15)}$ também comentaram sobre esse significado, destacando que no final de década de 90, houve uma mudança na qual pode ser observada "uma ênfase do linguístico para o pictorial e do alternativo rumo ao facilitador". Desse modo, foi possível confirmar que, no processo de terapia com afásicos, os sistemas alternativos de comunicação podem ser um apoio.

A idéia de "suplementar e alternativo" é de que na ausência da fala, o paciente poderá se comunicar. Ou seja, somente um limite articulatório impede o paciente de falar. Entretanto, alguns pacientes possuem alterações na linguagem e a "escrita por símbolos" também é afásica, como no caso da paciente M. Ela usa os símbolos com "perseveração". Desse modo, o sistema não é "alternativo", afinal há alteração de linguagem e de fala.

Quanto à implantação, há um período no qual os símbolos devem ser reconhecidos para depois serem utilizados. Eles devem compor partes do diálogo. A partir do uso do sistema, há um "texto" que pode ser interpretado pelo terapeuta e pelo paciente. A “comunicação alternativa” não deve ser ensinada, mas colocada em uso, caracterizado por histórias, narrativas e $\operatorname{rotinas}^{(7)}$.

Reafirmamos dessa forma, que a "escrita com símbolos" é um apoio terapêutico na terapia com afásicos. Em um primeiro momento, serve para que o paciente possa assumir um lugar de falante. Com os símbolos, ele "tem a palavra", o que promove uma mudança e um novo modo de enfrentar a dificuldade. A partir disso, diversas modalidades de linguagem são utilizadas para proporcionar um melhor caminho para cada caso. É o 
cruzamento dos gestos, símbolos, escrita e fala que garantem o diálogo mais fluente.

Vimos que no caso de M., o uso do sistema melhorou o reconhecimento visual, já que a paciente tem agnosia visual e, ainda, encaminhou o início de um trabalho com leitura e escrita - uma nova possibilidade de linguagem para este caso.

Já no caso J., os símbolos serviram de "texto base" para início de um diálogo. A paciente assume seu lugar de falante e utiliza gestos, símbolos, escrita e oralidade. Interessante, nesse caso, é que a oralidade aparece mais estável quando comparada com treinos isolados de fonemas.

\section{COMENTÁRIOS FINAIS}

Este trabalho pretendeu contribuir com uma rara discussão no campo da afasiologia: o uso do sistema suplementar e/ou alternativo de comunicação na terapia com afásicos.

Pode-se dizer que a CSA deve ser um método utilizado com afásicos severos. Entretanto, a implantação deve ocorrer no diálogo e, ainda, ser um suporte para a escrita e a leitura. Além disso, os símbolos evidenciam as dificuldades linguísticas dos pacientes, as quais estavam encobertas pela ausência da fala.

A CSA deve ser utilizada sempre associada com outras modalidades de linguagem na terapia com afásicos.

\begin{abstract}
It is known that the speech-language treatment of patients with severe aphasia is limited. Sometimes the absence of articulated speech is an obstacle to diagnose the aphasia. The patient with severe aphasia might not speak due to articulation inability, as it occurs in dysarthria and/or apraxia, and the absence of speech makes it difficult for speech-language pathologists to determine whether language is also impaired. The use of augmentative and alternative communication techniques has been an effective method for the rehabilitation of these patients. The aim of this study was to describe the use of the augmentative and alternative communication in therapy associated with other modalities of language (written language, gestures), based on the report of two cases of aphasia. Data analysis had two parts: introduction of augmentative and alternative communication in dialogue; and use of reading and writing associated with symbols. The augmentative and alternative communication supported oral language, reading and writing of the patients studied.
\end{abstract}

Keywords: Aphasia; Speech therapy; Nonverbal communication; Case reports

\title{
REFERÊNCIAS
}

1. Mansur LL, Radanovic M, Rüegg D, Zanotto de Mendonça LI, Scaff M. Descriptive study of 192 adults with speech and language disturbances. Sao Paulo Med J. 2002;120(6):170-4.

2. Souza TNU, Payão LMC. Apraxia da fala adquirida e desenvolvimental: semelhanças e diferenças. Rev Soc Bras Fonoaudiol. 2008;13(2):193202.

3. Ortiz KZ, organizadora. Distúrbios neurológicos adquiridos: fala e deglutição. Barueri: Manole; 2006.

4. Goldfarb R, Bader E. Espousing melodic intonation therapy in aphasia rehabilitation: a case study. Int J Rehabil Res. 1979;2(3):333-42.

5. Fonseca SC. O afásico na clínica de linguagem. [tese]. São Paulo: Pontifícia Universidade Católica de São Paulo; 2002.

6. Capovilla FC, Capovilla AGS, Macedo EC. O uso de sistemas alternativos e facilitadores de comunicação nas afasias. Distúrb Comum. 1998;9(2):233-59.

7. Pires SC, Limongi SCO. Introdução de comunicação suplementar em paciente com paralisia cerebral atetóide. Pró-Fono. 2002;14(1):51-60.

8. Almeida MA, Piza MHM, Lamônica DAC. Adaptações do sistema de comunicação por troca de figuras no contexto escolar. Pró-Fono. 2005;17(2):233-40.
9. Cherney LR, Halper AS, Holand AL, Cole R. Computerized script training for aphasia: preliminary results. Am J Speech Lang Pathol. 2008;17(1):19-34.

10. Millar DC, Light JC, Schlosser RW. The impact of augmentative and alternative communication intervention on the speech production of individuals with developmental disabilities: a research review. J Speech Lang Hear Res. 2006;49(2):248-64.

11. Jacobs B, Drew R, Ogletree BT, Pierce K. Augmentative and Alternative Communication (AAC) for adults with severe aphasia: where we stand and how we can go further. Disabil Rehabil. 2004;26( 21-22):1231-40.

12. Marshall J. The roles of gesture in aphasia therapy. Adv Speech Lang Pathol. 2006;8(2):110-4.

13. Marcolino J, Catrini M. O jogo entre falar/escrever/ler na clínica de linguagem com afásicos. Distúrb Comum. 2006;18(1):103-9.

14. Manzini EJ, Deliberato D. Comunicação alternativa - aumentativa. In: Manzini EJ, Campello JE, organizadores. Educação especial. São Luis: Imprensa Universitária; 1999. v. 6. p. 95-103. Coleção Prata da Casa.

15. Capovilla FC, Macedo EC, Capovilla AGS, Duduchi M, Gonçales MJ. $\mathrm{O}$ uso de sistemas alternativos e facilitadores de comunicação para o tratamento e a melhoria da qualidade de vida de afásicos. Mundo Saúde. 1996;20(10):337-42. 